\title{
Scenario Planning: Embracing the Potential for Extreme Events in the Colorado River Basin
}

\author{
Andrea K. Gerlak ${ }^{1}$ (D) - Katharine L. Jacobs ${ }^{2} \cdot$ Amy L. McCoy $^{3} \cdot$ Season Martin $^{4}$. \\ Mariana Rivera-Torres ${ }^{5} \cdot$ Anna M. Murveit $^{6} \cdot$ Amanda J. Leinberger $^{7}$. \\ Timothy Thomure ${ }^{8}$
}

Received: 25 September 2020 / Accepted: 26 January 2021 / Published online: 21 March 2021

(C) The Author(s), under exclusive licence to Springer Nature B.V. part of Springer Nature 2021

\begin{abstract}
Scenario planning (SP) has been increasingly utilized by water managers and planners in the 21 st century as climate and other uncertainties have challenged traditional planning approaches. This paper discusses the potential for scenario planning processes in the Colorado River Basin in the southwestern United States to build collective understanding of compound and cascading risks, and to identify possible solutions at multiple scales. Under the Colorado River Conversations Project, we convened a series of conferences and scenario planning workshops over the past 3 years to explore the potential to enhance the use of social and physical sciences in river management, and to broaden the community of people and entities engaged in discussions about managing the Colorado River. Working with a group of thirty water managers and other interested parties representing all 7 basin states, several Tribes, NGO's and Mexico, we used a participatory, mixed-methods approach to scenario planning that identified multiple drivers of change and developed eight science-based storylines from the intersection of these drivers. The development of the storylines and the subsequent conversations with participants about impacts and solutions resulted in a framework for understanding low probability-high consequence climate and other risks across the Colorado River Basin. We highlight three lessons that speak to the value and role of SP for fostering collaboration and creativity. These lessons include: (1) the importance of process in SP in fostering deliberate community building across sectors and geographies; (2) identifying challenges with engaging with uncertainty, complexity, and risk; and (3) determining what these findings mean for future SP in the Colorado River Basin and beyond.
\end{abstract}

Keywords Colorado River · Colorado River · Scenario planning · Colorado River Conversations Project

Andrea K. Gerlak

agerlak@u.arizona.edu

Extended author information available on the last page of the article 


\section{Introduction}

The management of the Colorado River is at an inflection point, and the decisions that are made in the next few years could have ramifications for generations. There are many issues of concern to be debated as stakeholders participate in the U.S. Bureau of Reclamation-led effort to determine operating guidelines for the river post-2026, a process termed Reconsultation. Among them are the diminishing flows associated with two decades of drought, predictions of further reductions associated with climate change, issues associated with managing the river to meet the often-conflicting needs of a broad array of stakeholders, and a range of implications for natural ecosystems and human communities.

The Colorado River provides water supplies to close to 40 million people in the U.S. and Mexico. The mainstem of the river is a highly engineered system, with multiple dams and enough storage capacity in Lakes Mead and Powell to meet downstream water delivery obligations for a four-year period. However, after two decades of drought the reservoirs are now at less than half capacity. There is a rapidly growing understanding that 1) the river itself is over-allocated, meaning total demands outpace the volume of water that flows into the reservoirs in an average year (Kuhn and Fleck 2019) and 2) climate change is expected to continue to reduce flows into the future (Udall and Overpeck 2017; Milly and Dunne 2020).

The Colorado River is managed under a series of laws, court decisions, and other documents often referred to as the Law of the River (Stern and Sheikh 2020). Its origin was the 1922 Colorado River Compact, which was a reaction in part to concerns of upper basin states that planned water development projects in the lower basin would deprive them of future access to the river (US Bureau of Reclamation 2019). Notably, the Compact was developed during a relatively wet period (US Bureau of Reclamation 2012; US Department of the Interior 2020); therefore, the initial water apportionments exceed average river yield, even during "normal" periods. For times of drought, the river is operated under the 2007 Interim Guidelines, which established coordinated operating criteria for Lake Powell and Lake Mead and water surface elevation criteria to define tiers of shortage and the resulting apportionments of water (US Secretary of the Interior 2007). These guidelines are in effect through 2026. However, by the mid-2010s, it was recognized that additional actions beyond those identified in the 2007 Interim Guidelines would be necessary to avoid catastrophic shortages if the ongoing multi-decade drought persists. Between 2015 and 2019, additional voluntary agreements were negotiated to reduce shortage risks, collectively referred to as the Drought Contingency Plan (DCP) in the U.S. and the associated Binational Water Scarcity Contingency Plan in Mexico (Stern and Sheikh 2020). With the 2026 expiration of the 2007 Interim Guidelines and related DCP agreements looming, the Reconsultation process has been initiated to establish Colorado River operating criteria for the future.

Further, there is an increasing sense of urgency to the ongoing Colorado River negotiations as projections of future water yield in the basin can vary widely within a short timeframe, and generally worsen over time. In April 2020, the U.S. Bureau of Reclamation projected that the chances of a lower basin shortage of any magnitude was 55\% by 2024 using the "Stress Test" assumptions of hydrology, which reflects the current multi-decadal drought. In the same projections, there was no significant percentage chance of a deep (Tier 3) shortage from 2020-2024 (US Bureau of Reclamation 2020a). Within a four-month period, these projections changed considerably, and for the worse. The August 2020 projections indicated that the chance of lower basin shortage by 2024 was $65 \%$, a $10 \%$ increase in just four months, and the number increased even further to $77 \%$ by 2025 . The chances of a deep Tier 3 shortage also jumped from negligible to 
$19 \%$ by 2025 (US Bureau of Reclamation 2020b). These worsening conditions and the wide variability within short timeframes create both concern and uncertainty.

Over the longer term, shortage risks are expected to increase because of climate change. Temperatures are projected with high confidence to generally increase, which has the dual impact of shifting seasonal precipitation patterns (e.g. less snowpack) and potentially increasing evaporative losses (Dettinger et al. 2015). Modeling projections of mean annual precipitation in the future vary, though there is high confidence that precipitation extremes are already becoming more commonplace and that trend will continue; the dry times will become even drier and the wet times will be wetter (Dettinger et al. 2015). The combination of warming temperatures and shifting precipitation patterns will impact the availability of water resources in the Colorado River. Further, due to anthropogenic climate change effects, multi-decade periods of low runoff in the Colorado River basin could result even if there is an increase in mean precipitation (Udall and Overpeck 2017).

In this context, the Colorado River Conversations Project (CRCP), led by the Center for Climate Adaptation Science and Solutions (CCASS) at the University of Arizona, has actively supported exploration of these issues through conferences, small-group discussions, and scenario planning activities. Over a three-year period (2017-2019), CCASS hosted three large conferences with over 100 people at each event, bringing together physical and social scientists, representatives of all 7 basin states, Mexico, multiple Tribes, municipal, agricultural and electric power sectors, and a wide array of non-governmental organizations. Funded by the National Science Foundation, the Walton Family Foundation and other private family foundations, a primary motivation for these activities has been to increase the use of social and physical science in river management activities and to broaden the spectrum of participants in conversations about the future risks and solutions in the Colorado River Basin. In addition, our CRCP team experimented with more effective ways to integrate knowledge from a range of disciplines and experience, and to facilitate relationships between participants who might not otherwise have occasion to work together.

In the first conference in 2017, water managers, social and physical scientists identified important gaps in scientific knowledge and existing data, as well as useful tools that were not fully utilized by decision-makers. During the subsequent conference in 2018, water managers and an array of other practitioners responded to the initial findings of the scientists, and then established priorities for next steps. Their top two priorities were to 1) hold a science conference focused on interdisciplinary information that could be useful in developing a more sustainable future for the river and 2) develop a SP process that focused on low probability, high consequence events that are clearly possible but rarely discussed in public. With help from the Walton Family Foundation, we took up both charges and in the spirit of experimentation, we initiated a new SP process in the Colorado River Basin.

River basin management is fraught with uncertainty, as patterns of water supply and demand are

impacted by complex climate, ecological, social, economic, and institutional dynamics (Scott et al. 2012). When used appropriately, SP can be a powerful, practical, and intuitive tool for long-term decision-making under conditions of deep uncertainty (Kang and Lansey 2014; Mahmoud et al. 2009; Means et al. 2005). SP allows resource managers to evaluate and prepare for a range of plausible futures, build a shared understanding of how and why alternate futures evolve, identify thresholds in the system, and craft strategies to better adapt to changing conditions (Mahmoud et al. 2011). Planning for a range of possible futures can increase flexibility and add robustness to the system, improve responses to changing conditions, 
maintain reasonable costs, and preserve public trust (Kang and Lansey 2014). SP is also considered a powerful communication and stakeholder engagement tool, through the creation of qualitative storylines that are often more accessible than quantitative models and graphs (Bohensky et al. 2006). Since water resources decision making often involves widely diverse points of views, values, and priorities, process-driven initiatives, such as SP, can be important vehicles to foster mutual understanding and develop consensus about goals and priorities, as well as establish a shared vision for the future (Baker et al. 2004).

Between 2019 and 2020, our project team designed and facilitated an exploratory SP process to collectively co-create a broad set of scientifically supported "what if" storylines that explore the implications of low probability/high consequence climate events, as well as a range of other drivers that influence risk. We asked: what are plausible black swan events that could occur within the context of extreme climate conditions? Our SP efforts have focused on explorations of the potential for extreme events to disrupt the multiple services currently provided by this "hardest working river in the west" (American Rivers and Western Resources Advocates 2014). The goal has been to create a "safe space" where water utility managers, state agency representatives, tribal members, NGOs and others could discuss the potential risks and ramifications of multiple intersecting extreme events and express their fears and ideas without the usual pressure of attribution (Pulwarty et al. 2005).

In this paper, our team of faculty members, students and practitioners draw on our observations of the events and interactions described above and discuss the results of participant surveys at the SP workshops. In the following sections, we first review the literature on SP, with a special focus on how SP exercises have been used in river basin management broadly, and more specifically in the Colorado River Basin. We then describe our SP approach, followed by in-depth discussion of the storylines that emerged. We also describe the categories of impacts that the group identified within the final four selected storylines, discuss process related observations from the participants, and conclude with findings related to the value and role of SP for the Colorado River Basin, and other river basins around the world.

\section{Scenario Planning for River Basin Management in the Era of Climate Change}

Scenario Planning (SP) is an effective tool used in environmental decision-making and planning that acknowledges the limitations of "best-guess" projections and allows natural resource managers to plan for future uncertainties (Maier et al. 2016; Star et al. 2016). The Intergovernmental Panel on Climate Change (IPCC) define a scenario as a "plausible and often simplified description of how the future may develop, based on a coherent and internally consistent set of assumptions about driving forces and key relationships. Scenarios may be derived from projections but are often based on additional information from other sources, sometimes combined with a narrative storyline" (Intergovernmental Panel on Climate Change (IPCC) 2008). Scenarios are "snapshots of plausible futures" that illustrate how unpredictable forces develop over time to explore risks and opportunities; they are often used by public managers to identify strategies to adapt to climate change and work towards preferred outcomes (Garfin et al. 2015). SP allows managers to strategically envision an assortment of possible futures that highlight key areas of uncertainty, as well as identify broad options for living within those areas of uncertainty. These futures may be near-term and simple, or they may be long-term and complex, addressing highly uncertain interactions (Moore et al. 2013). 
SP comes in different shapes and forms - qualitative (through narrative or graphic illustrations), quantitative (using computer modeling systems), normative (based on present conditions) and exploratory (envisioning a plausible end state). SP initiatives can be research-driven, participatory, or a combination of the two (Star et al. 2016). Through participatory approaches, such as workshops, SP efforts create venues for meaningful dialogue, through which diverse viewpoints about potential futures can be captured to find pathways for robust decisionmaking (Garfin et al. 2015). SP is thought to be most effective when it produces multiple plausible futures, rather than focusing on preferred alternatives (Star et al. 2016), and when it adopts an iterative process (Mahmoud et al. 2011).

Further, limitations arise when internal and external uncertainties are not properly assessed (Dong et al. 2013; Scott et al. 2012). Some models fail to incorporate a full range of risk and variability, to generate sufficiently diverse scenarios, and to move beyond discrete scenarios towards continuous ones that cover a full range of conditions (Dong et al. 2013; Garrick et al. 2008, Mahmoud et al. 2009; Scott et al. 2012: 850). Further, SP's biggest limitation relates to its "inherent subjectivity" required to develop scenarios (Mahmoud et al. 2011).

As a tool, scenario planning has been applied in different river basins across the globe to help regions move beyond "business-as-usual" planning methods (Baker et al. 2004; Bohensky et al. 2006: Hoff et al. 2011; Lautenbach et al. 2009; O’Connor et al. 2005; VanRheenen et al. 2004). Workshops are a common method to engage diverse stakeholders to identify critical issues, drivers, challenges, and opportunities that may not be apparent and can guide strategic thinking to build and reassess strategies that are robust to a diverse range of futures. SP can help managers identify water supply and demand trends, reconcile competing objectives, identify key tradeoffs by assessing social, economic, and environmental impacts of different policy alternatives at multiple scales, capture spatial and temporal dynamics, and address complex large-scale challenges under conditions of deep uncertainty (Bohensky et al. 2006; Hoff et al. 2011; Li et al. 2009; Pallottino et al. 2005; Weng et al. 2010). In addition, water managers can move from planning to action by identifying common elements - projects or programs that are viable under a wide range of future scenarios - to have a higher degree of confidence when making low-regret financial investments in the near-term (Marra and Thomure 2009).

SP has been increasingly utilized by water managers and planners in the Colorado Basin in the 21 st century as climate uncertainties, and other uncertainties such as population growth, have challenged traditional planning approaches (Garrick et al. 2008). The geographic scale of these efforts and the actors engaged have varied. At the larger basin scale, SP efforts have been organized through partnerships of federal agencies, utilities, and researchers to engage stakeholders and the public. In the 2012 Colorado River Basin Supply and Demand Study ("Basin Study"), USBR shared management responsibilities with Basin State representatives to work with diverse stakeholders and the public in various levels of participation from management, project, and technical teams to public comment opportunities (US Bureau of Reclamation 2012). Similarly, the 2018 Colorado River Basin Ten Tribes Partnership Tribal Water Study ("Tribal Water Study") was a collaborative effort between USBR and the 10 Tribes Partnership, which involved tribal councils, members, staff, and attorneys of Partnership Tribes. Their SP efforts developed four storylines of future tribal water development (US Bureau of Reclamation and Ten Tribes Partnership 2018).

Scenario planning efforts can also be effective at smaller regional or city scale as seen in Colorado's Front Range, the Phoenix Metro Area, the Central Arizona Project, the City of 
Tucson Water Department, Riverside County, the Upper Gila Watershed, and the Verde Valley (Waage and Kaatz 2011; Gober 2008, 2014; Gober et al. 2016; Sampson 2015; Scott et al. 2012; Kang and Lansey 2013, 2014; Mott Lacroix et al. 2015; Mahmoud et al. 2011; Mahmoud 2018; Groves et al. 2008). Denver Water led a collaborative SP process that engaged other Front Range utilities in the development of regional hydrologic models and common assumptions for planning across the region (Kaatz and Waage 2011). The Resilient and Sustainable Infrastructures (RESIN) program of the Emerging Frontiers in Research (EFRI) division of the U.S. National Science Foundation (NSF) led a SP process in Tucson, which engaged the University of Arizona, City of Tucson Water Department, and Pima County Regional Wastewater Reclamation Department staff (Scott et al. 2012). In contrast, the Central Arizona Project's SP process is internal, as are aspects of Denver Water's SP process (Kaatz and Waage 2011; Mahmoud 2018). Scenarios often focus on supply, demand, intersections of supply and demand, or the intersection of supply, demand, and a third factor such as public perception of potable water reuse (US Bureau of Reclamation 2012; US Bureau of Reclamation and Ten Tribes Partnership 2018; Waage and Kaatz 2011; Gober 2008, 2014; Gober et al. 2016; Sampson 2015; Scott et al. 2012; Kang and Lansey 2013, 2014; Mahmoud et al. 2011; Mahmoud 2018; Groves et al. 2008). The time horizon for SP studies in the Colorado River Basin have ranged from 25 to 60 years (US Bureau of Reclamation 2012; US Bureau of Reclamation and Ten Tribes Partnership 2018; Gober 2008, 2014; Gober et al. 2016; Scott et al. 2012; Groves et al. 2008).

\section{Designing a Scenario Planning Process for the Colorado River Conversations Project}

The SP process developed for this project involved a deliberate blending of methodologies to address the unique context, hydrological conditions, and current social dynamics of the Colorado River Basin (Intergovernmental Panel on Climate Change (IPCC) 2008; Moore et al. 2013; Stratus Consulting and Denver Water 2015). The process was designed as an iterative and participatory conversation to extend beyond the traditional planning parameters and to offer water managers an opportunity to consider the uncomfortable extremes that keep them up at night and may be outside the capacity of a utility or agency to absorb or discuss (Garrick et al. 2008; Garfin et al. 2015; Star et al. 2016).

In our approach SP was used as a tool for structuring our conversations, without an intention to select a desired set of paths or a specific outcome. Our process explored drivers of impacts, the effects of compound events, and potential solutions that could reduce harm locally and across the Basin. We sought to address the fact that the majority of the decisions that affect the River are made at the sub-basin, state, tributary or utility/district/tribe scales, even while many conversations occur at the Basin level. Therefore, we intentionally designed an approach that could be workable at the basin scale, but that could be used as a framework for management entities who were interested in exploring these issues in a decision-scale context.

Approximately 30 people participated in the three SP workshops in 2019 and 2020, representing municipal water managers, Tribal members, NGO members, agricultural representatives, academics, and federal agencies across the seven basin states, sovereign Tribes, and Mexico. The advisory committee of the larger CRCP, comprised of twelve broadly respected Colorado River experts in the region, helped to nominate and select participants for the SP 
process. The CRCP advisory committee played a pivotal role in grounding the project and in moving the process forward. Participants were selected for their expertise in SP, climate science, and decision-making processes as well as for tribal, sectoral, and geographic representation.

The objectives of the SP process were twofold: 1) build a space where all participants were eager and comfortable to fully engage in the conversation, and 2) develop substantive storylines outlining plausible low probability, high impact futures and a low regrets solution set to mitigate impacts in those futures. Across the three structured workshops, discussion among participants evolved, illustrating increased levels of understanding and connection across sectors and geographies. The storylines they developed represented a broad set of potential risks for the Colorado River Basin, while the solutions included many that could prove useful across multiple scenarios (i.e. common elements).

The freedom to engage in challenging conversations about risk, extreme events, and possible extreme futures was enabled through several aspects of this SP process: 1) agreement not to attribute any comments made in our process to any individual; 2) adoption of a lighthearted approach to brainstorming a range of physical and non-physical "nightmare" drivers, 3 ) the design of the storylines around the intersection of three drivers, 4) the selection of storylines that maximized the breadth of possible futures; 5) identification of a range of impacts that might occur under each storyline, and 6) a collaborative discussion around developing and selecting low-regret solutions that could reduce multiple risks.

The SP planning process included six steps that were conducted sequentially over the course of ten months, within the three workshops (Figure 1).

1. Setting the Context. This activity focused on exploring areas of uncertainty outside the parameters of most planning discussions and identifying low-probability but nonetheless plausible events that could occur within the context of extreme climate conditions (Figure 2). The geographic scope of the project included the entire basin within the U.S., Mexico, and sovereign tribal nations, while the planning horizon extended through about 2050 to incorporate the near-term renegotiation effort, as well as longer-term management conditions under new guidelines.

We initiated the SP process with a film designed to introduce the river to the group, noting that the river itself needed to be acknowledged. Our intent was to demonstrate our respect for the river, and the many ways in which it affects every life in the basin. Everyone in the room stood during the film, taking a moment to acknowledge the life of the river before moving on to introducing each person. The film appeared to have a profound impact on the group and influenced the quality of the following conversations.

2. Identification of Drivers. A driver, or driver of change, is something that influences a plausible future and is distinct enough to determine the potential impact it will have on that future (Nelson et al. 2006). Scenarios are constructed using the most important and uncertain driving forces of change (US Bureau of Reclamation and Ten Tribes Partnership 2018; Kaatz and Waage 2011; Scott et al. 2012). In the Basin Study, for example, drivers of water demand included population growth, water use efficiency, irrigated acreage, and water use for energy (US Bureau of Reclamation 2012). The importance of a driver is the likelihood/magnitude of a positive or negative impact, and the uncertainty of the driver is determined by how much is or is not known (O'Connor 


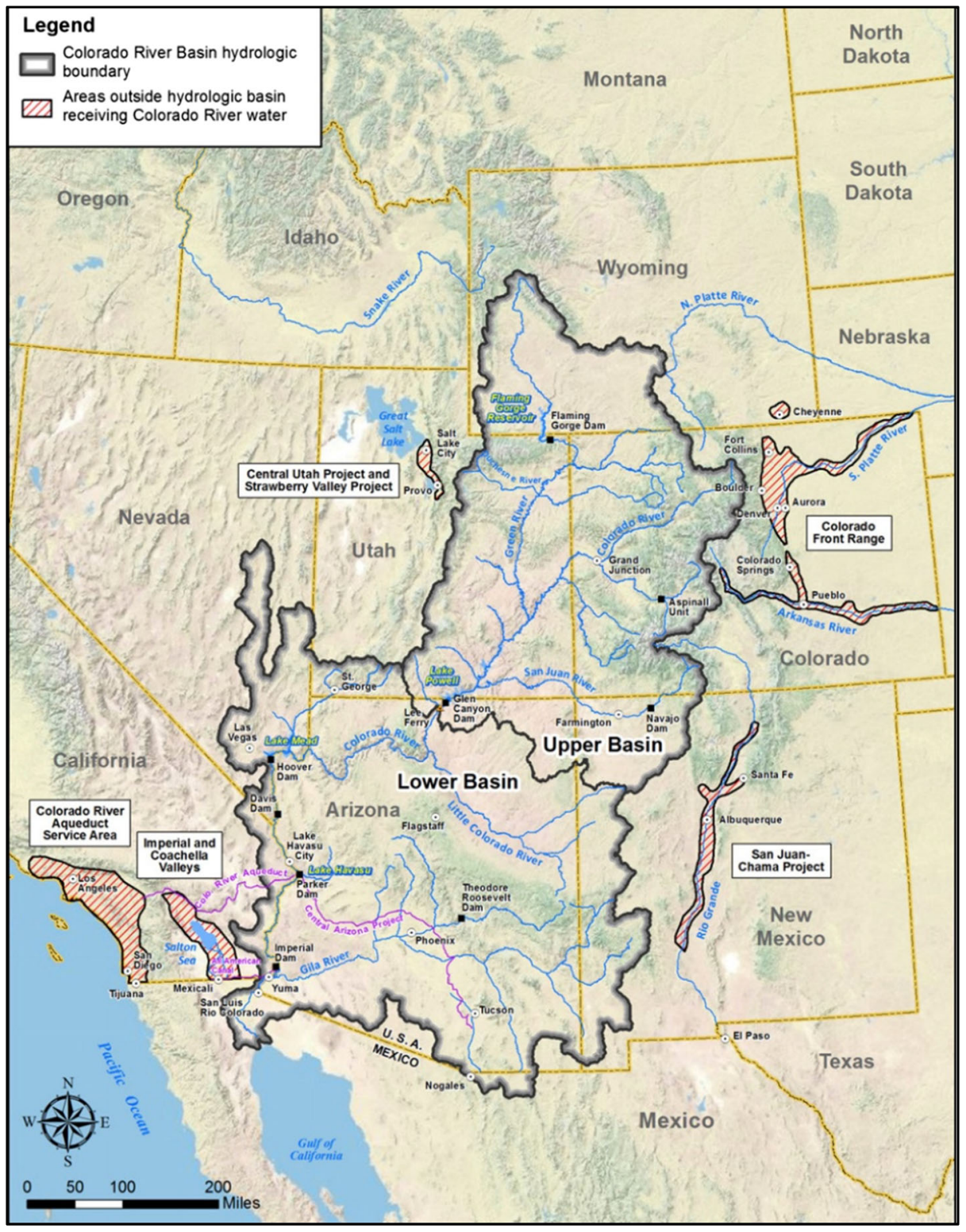

Figure 1. Map of the Colorado River Basin

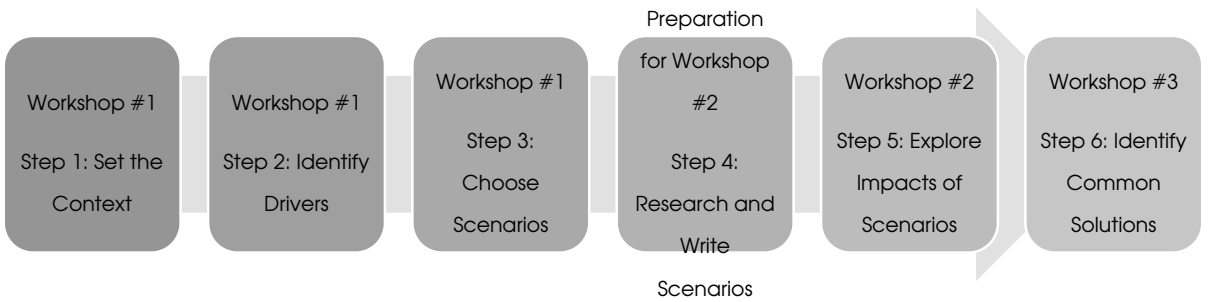

Figure 2. Colorado River Conversations Project SP Approach here 
et al. 2005). Drivers of change can cause one or many disruptions which can lead to unprecedented extreme outcomes.

From the perspective of water managers, climate and hydrologic extremes are inextricably linked. Drivers of extreme conditions are caused by the intersection of natural variability and other climate factors (including anthropogenic warming). They affect future temperatures, precipitation, and other global climate patterns. The impacts include changes in the location, duration, frequency, intensity, timing and context of hydrologic events such as droughts or floods (National Research Council 2016). To acknowledge the influence of climate conditions on plausible future scenarios, climate extremes served as the master variable in each storyline. However, the relationship between changing climate conditions and shifts in water supplies is not the only trigger for potentially disruptive future conditions. Other drivers are important to consider as well, such as changes in demand, supply augmentation, technology, land use planning, energy availability and costs, water law issues, economic conditions, changes in governance, and regulations (Stratus Consulting and Denver Water 2015).

When asked what their nightmare future conditions might look like and what drivers might lead to those conditions, stakeholders named and described over 70 distinct "nightmares" that informed a list of 35 drivers in nine categories: Climatic, Governance, Ecological, Legal, Economic, Social, Political, Physical, and Other (Figure 3).

3. Scenario Selection. To develop the scenarios, participants chose three drivers identified in Step Two and mapped their intersections using three axes as shown in Figure 4. From the intersection of the three drivers, eight possible future scenarios were named and described within the axes. With multiple breakout groups engaging in this conversation, a total of 24 possible storylines for further consideration emerged.

4. Scenario Storyline Development. Drawing from the list of intersecting drivers, eight initial storylines were selected by the participants to illustrate diverse hypothetical futures, incorporating at least one climate driver and two additional drivers. The intent of looking at the intersection of more than two drivers was to emphasize the importance of compound stresses in creating extreme events. The descriptions of the initial storylines were later developed into more complete products informed by data, modeling forecasts, and research findings from peer-reviewed literature, to ensure a scientific grounding for the plausibility of proposed future conditions. Additionally, and where

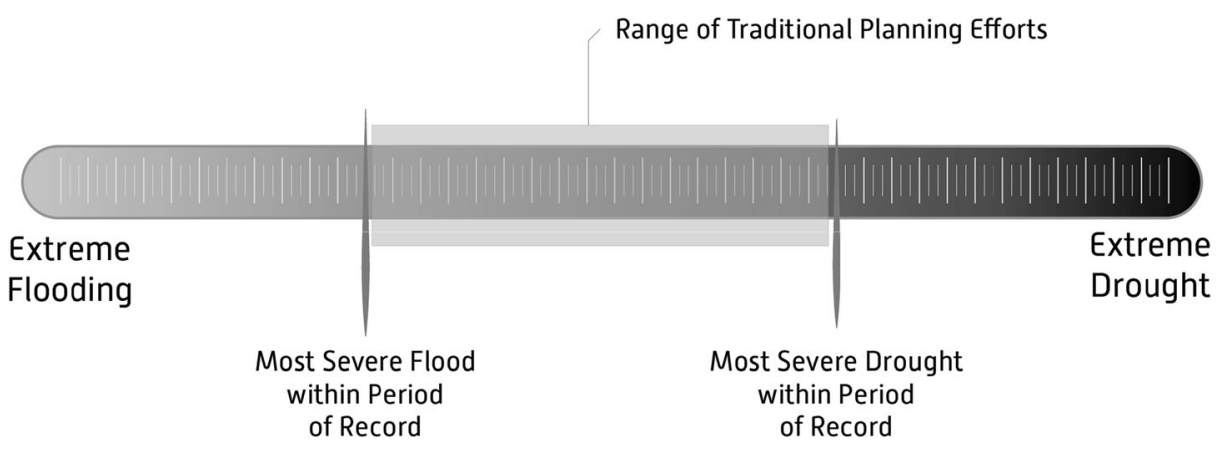

Figure 3. Scope of Scenario Planning Workshop here 


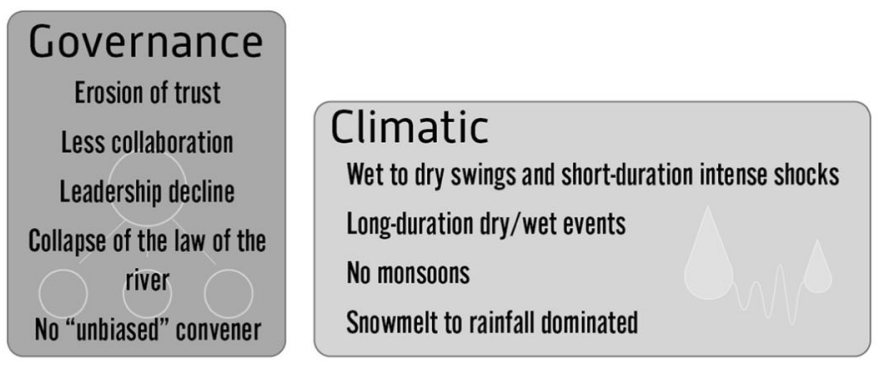

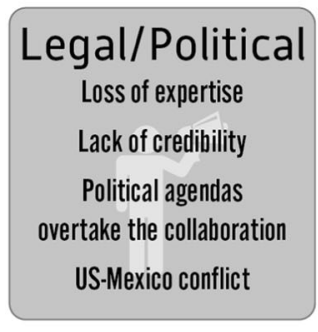

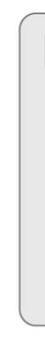

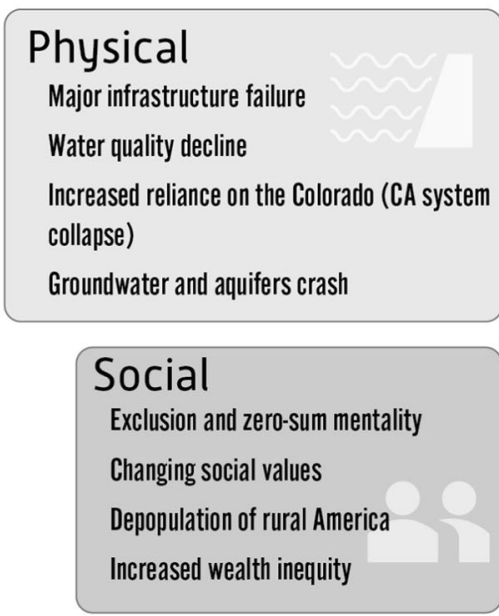

\section{Ecological}

Keystone species extinction

Landscape scale wildfire

Loss of ecosystem values

\section{Economic}

Changing energy needs

Economic recession

Growing urban/rural divide

Demographic shifts

Tribes lose full value of water

Figure 4. Key Drives Identified in June 2019 Workshop here

appropriate, the storylines were informed by notable historic conditions, such as infrastructure failure, economic crashes, and social upheaval (See Appendix A for an example storyline). The aim in drawing from multiple sources of information was to lend scientific, cultural, and social legitimacy to each proposed future storyline. The eight storylines included:

1. Caught Off Guard: Wet to Dry Swing, Governance Failure, Infrastructure Failure

2. Dig It Deeper: No Monsoon, Aquifer Crash, Tribal Engagement in the Lower Basin

3. Unfair and Arid: Long Duration Dry, Increased Wealth Gap, Decrease Inclusivity

4. Sad Skiers: Snow to Rain, Low Environmental Values, Decrease in Recreational Economy

5. Water on the Move: Wet to Dry, Increase in Markets, Tribal Engagement in the Upper Basin

6. Disaster Strikes: Short System Shock (Wet to Dry), Collapse of California Water Systems, Poor Economy

7. Rural Revival: Long Duration Dry Conditions, Transition from Global to Local Economies, Rural Agricultural Investment

8. Flood Gates: Dry to Wet Swing, Technological Advances Enhance Supply, US-Mexico Collaboration 
5. Impacts of Storylines. Working from the proposed storylines, participants brainstormed a range of impacts that could plausibly occur in a future defined by each storyline. The Categories of Impacts were parsed into six groups: Legal/Political, Governance, Ecological, Physical, Social, and Economic. By design, the impacts of each storyline varied widely within each of the six categories and captured cascading effects, system failures, and unexpected consequences. Interestingly, while most impacts discussed were socially, economically, legally, or hydrologically adverse, there were some potentially positive impacts that were discussed as well.

Most notably, long-duration dry conditions and water scarcity could shift leadership and power dynamics towards those who hold the highest priority water rights, namely Tribes with Colorado River allocations and mainstem agricultural districts. As an example of a possible social/economic implication, this shift could position the Tribes and specific agricultural entities to take greater leadership roles in basin management, while other water use sectors might need to assume a greater portion of water curtailments (US Bureau of Reclamation and Ten Tribes Partnership 2018).

6. Low-regret Solutions. As a final step in the SP process, the project team re-configured the eight storylines to streamline and remove any redundancies or overlap in impacts. Four storylines that included elements from the eight original scenarios were crafted, each of which painted different future trajectories (Figure 5). While the majority of drivers are negative, some drivers such as increased tribal engagement, could bring positive change to the Colorado River Basin.

SP participants agreed that there are many types of extreme events that are nearly impossible to prepare for, especially in the context of compound stresses and the potential for system failure. That said, there was great interest in exploring whether there were solutions that could mitigate impacts over a broad range of possible events (i.e. common elements). Having concluded that there are likely to be few "no-regrets" solutions, participants methodically brainstormed potential "low-regret" solutions that responded to impacts across the six categories listed above for the four final storylines. At the end of the final workshop, the group had identified fourteen low-regret adaptation Solution Types that could apply to multiple futures under most conditions and would therefore be worth considering in greater detail in future conversations. The range of Solution Types were grouped into four categories: Social, Economic, Science, and Governance (Table 1).

With COVID-19 as the backdrop, the final workshop was conducted virtually and focused on developing a list of potential responses that could apply to most of the storylines and many of the potential future impacts. Meeting virtually in the context of a pandemic made the discussion about extreme events much more present and credible, which significantly enhanced the quality of the conversation even though the group could not meet in person. Among the solutions that could reduce risk under multiple stresses, the group focused on the fundamental importance of building and maintaining relationships and trust across governance institutions (from local to federal), water-use and management sectors, and geographies. There was a significant emphasis from SP participants on identifying new opportunities for collaboration, with entities assisting each other in finding and fostering ways to support each other, and coalition building. The participants noted that they wanted to extend the group 


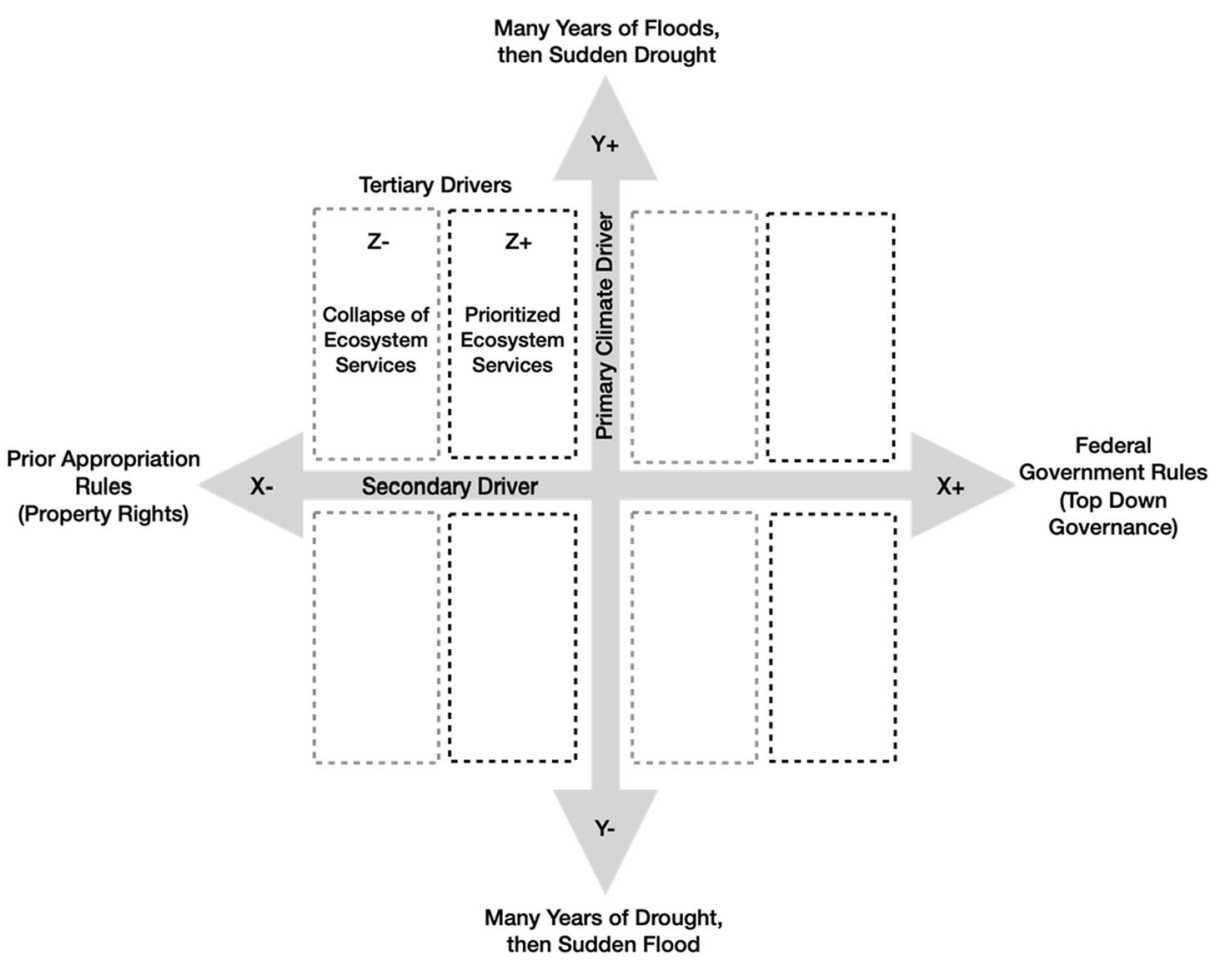

Figure 5. Three-Dimensional Matrix for Organizing Drivers into Scenarios here

conversations started within this process beyond the tenure of this SP series to find new and innovative ways to work together to collectively manage risk. The remainder of the solutions focused on increasing flexibility and agility (especially in the context of current institutional barriers), pursuing strategic financial and water supply reserves that could be deployed during times of crisis and shortage, and doing a better job of integrating current scientific research and data into decision-making processes.

\section{The Value and Role of SP for Fostering Collaboration and Creativity}

Participants provided formal feedback following the second and third workshops on their experiences in the workshops and the larger SP process, as well as how they may (or may not) integrate their experiences into their own management, research, advisory, or advocacy efforts. Overall, feedback was very positive, with participants expressing enthusiasm for the process as well as an interest in continuing the conversations beyond the tenure of the project itself. We draw from this feedback and our reflections to highlight some major lessons that speak to the value and role of SP for fostering collaboration and creativity.

\subsection{Process Matters}

Participants in this process consistently reported that the project opened a new set of conversations and essentially gave them "permission" to start engaging in challenging discussions 


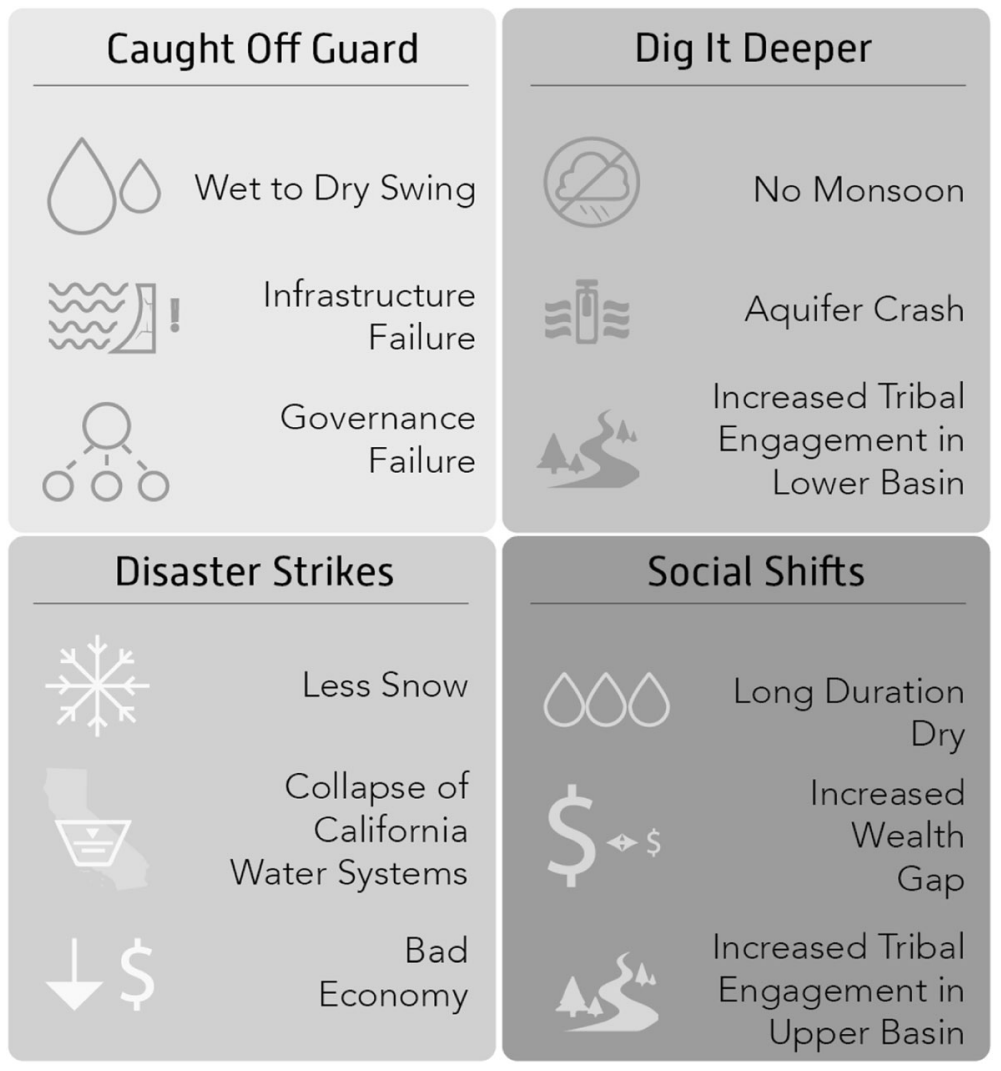

Figure 6. Final four storylines adopted in SP process here

(See Box 1). SP participants noted that they felt free and inspired to talk collectively about low probability but high consequence futures that would impact both their own jurisdictions as

Table 1. Categories of Risk Management Responses

\begin{tabular}{|c|c|c|c|}
\hline Social & Economic & Science & Governance \\
\hline $\begin{array}{l}\text { Collaboration and } \\
\text { alliance-building across } \\
\text { sectors }\end{array}$ & $\begin{array}{l}\text { Developing } \\
\text { creative/collective fi- } \\
\text { nancing for implemen- } \\
\text { tation of solutions }\end{array}$ & $\begin{array}{l}\text { Access to best available } \\
\text { science for } \\
\text { decision-making }\end{array}$ & $\begin{array}{l}\text { Solutions with } \\
\text { co-benefits } \\
\text { across regions } \\
\text { and sectors }\end{array}$ \\
\hline $\begin{array}{l}\text { Expanding and building water } \\
\text { leadership across the basin }\end{array}$ & $\begin{array}{l}\text { Potential for collaborative } \\
\text { solutions across } \\
\text { partners can reduce } \\
\text { costs }\end{array}$ & $\begin{array}{l}\text { Connecting benefits of water } \\
\text { management, } \\
\text { environmental systems, } \\
\text { and public health }\end{array}$ & $\begin{array}{l}\text { Greater flexibility } \\
\text { for water } \\
\text { transfers }\end{array}$ \\
\hline $\begin{array}{l}\text { Diversifying options for } \\
\text { communicating hydrologic } \\
\text { risk }\end{array}$ & $\begin{array}{l}\text { Investments in Tribal } \\
\text { infrastructure, } \\
\text { capacity, and water } \\
\text { supplies }\end{array}$ & $\begin{array}{l}\text { Research into multiple water } \\
\text { supply benefits of } \\
\text { watershed management }\end{array}$ & $\begin{array}{l}\text { Redundant water } \\
\text { supplies and } \\
\text { strategic water } \\
\text { reserves }\end{array}$ \\
\hline $\begin{array}{l}\text { Develop contingency plans and } \\
\text { continuity of operations } \\
\text { planning across multiple } \\
\text { scales }\end{array}$ & $\begin{array}{l}\text { Financial incentives to } \\
\text { promote and } \\
\text { strengthen regional } \\
\text { cooperation }\end{array}$ & $\begin{array}{l}\text { Best practices for } \\
\text { implementing technology } \\
\text { solutions (e.g. green } \\
\text { infrastructure) }\end{array}$ & $\begin{array}{l}\text { Water } \\
\text { conservation } \\
\text { and demand } \\
\text { management }\end{array}$ \\
\hline
\end{tabular}


well as the Basin. The final workshop was held virtually because of the COVID-19 pandemic. Not surprisingly, the emerging global and national pandemic added a layer of realism about extremes to this SP process and fostered an added layer of social cohesion to the group. Beginning in February 2020, the plausibility of an extreme event that could radically alter the way that business is conducted became real in a way not imagined at the start of this SP process.

\section{Box 1: Comments from Participants re: Value of the CRCP Scenario Planning Process}

- The interests and perspectives shared were very valuable. [This workshop series] helps me learn more about others who are dependent on Colorado River water. It allowed me/challenged me to think outside the box about the Tribes role in the renegotiation process. October 2019

- This process was helpful and perhaps it can be used as a seed for a broader basin-wide effort. October 2019

- I think this workshop's scenario planning process is helpful in pushing the boundaries of participants thinking in terms of planning for the future and addressing uncertainty. October 2019

- having so many voices in the room was a refreshing reminder of the diverse set of users of the river and the difficulties that arise with trying to maximize river benefits (for people and the environment) while simultaneously reducing inequities. April 2020

- The value of relationship building as a key outcome of a scenario planning exercise. This really was fantastic. April 2020

- We have all grown, matured, developed trust, and relationships across the stakeholder community in the basin. We have developed a better understand of each other's realities. Moving forward, we should continue to do this with this type of group So valuable for me personally in helping me understand what are the issues that are really important as we think about the guidelines or what Arizona has to deal with over the new few years or decades... We have made investments in relationships, built a culture or responsibility and respect. April 2020

Many participants noted the importance of a broader and more sustained conversation among Colorado River Basin interests to address challenges ahead. In previous efforts, such as the 2007 Surplus Guidelines, negotiations involved the US seven basin states, the federal government, irrigation districts, and respective water agencies. Other stakeholders, including NGOs, tribes, and the IBWC were only allowed to contribute during the US National Environmental Policy Act (NEPA) mandated public comment period (Berggren 2018). One workshop participant noted that, "it is a fair criticism that states have left others out of the decisions until the end." Another described previous efforts as "shuttle diplomacy," because environmentalists and others were not included in direct negotiations but managed to insert their perspectives through informal means of consultation and input. Based on those experiences, there are increasing efforts to expand opportunities for participation in future processes, and this SP process laid the groundwork for strengthening partnerships and a shared conversation about future risks.

The involvement and contributions of diverse participants was essential to creating a collective understanding of risks, trade-offs, and possible management actions. In developing scenarios around climate change and other stresses, the workshop process offered a way to articulate the potential consequences of risks and uncertainty in a way that empowers decision makers to prepare and respond both within their jurisdiction (based on their local knowledge) and in collaboration with other decision-makers in the Basin (Baker et al. 2004; Bohensky et al. 2006: Hoff et al. 2011; Lautenbach et al. 2009; O'Connor et al. 2005; VanRheenen et al. 2004). Importantly, this approach to SP relied on the degree to which the storylines were legitimately plausible (and/or conceivably possible, even with a very low probability) to the participants (Scott et al. 2012).

As evidenced in many comments from participants, a culture of responsibility and commitment to a more solutions-based focus emerged over the course of the SP workshop series. 
This emotional bond among the participants and a shared resolve to working on solutions started with the film that introduced the river in our first workshop. SP participants quickly recognized, and appreciated, that these discussions were really about the vulnerability and resilience of every person's livelihood in the basin, as well as of the river itself. Viewing the river as an entity that deserves respect is the lesson that Tribal participants shared in virtually every conversation in our conferences and SP workshops, and it appeared to permeate the entire group's perspective. This realization that we could create community through a film (including images and music) as well as through our selection of participants, facilitation techniques, storylines, and the structure of the discourse, was an important discovery that could be useful in other contexts.

Noting the creativity, sophistication, and level of detail that the participants brought to the workshops, the project team and participants realized that people do not need to be long-term water experts to contribute to the river management process. Importantly, people who had felt historically excluded now reported that they felt an imperative to participate and bring new perspectives based on their relationship to: a) the conditions of the river, b) the results of water management decisions, and c) their own responses to an uncertain future. In addition, the enthusiasm around the workshop experience suggests that universities can play a role in developing, holding, and supporting a neutral space for new and boundary-pushing conversations (Gober et al. 2011; Scott et al. 2012). This suggests a potential opening for new engagement pathways and processes in the Colorado River Basin (Karambelkar and Gerlak 2020).

\subsection{Engaging around Uncertainty, Complexity, and Risk}

SP participants widely acknowledged that risk perception depends on each stakeholder's context, location in the basin, and many other factors. One participant noted that the threats to the system thus far have been relatively modest. "Our systems have not faced significant threats, most of them have been relatively gentle by comparison. As problems become more complex, the system is more difficult to handle, which will reduce our capacity to respond." Yet, the group expressed concern that tipping points in the system remain unexplored. Participants struggled with questions of uncertainties associated with knowing when the system might "break" and why, and with understanding what stresses the system can and cannot handle. The modern reality of the COVID-19 pandemic further emphasized to some participants their own vulnerability and potential risks. According to one participant, "this workshop series provided a firm reminder that the possibility of catastrophic events should be included in the long-term planning process (made ever clearer by COVID-19). An understanding of 'what breaks the system' is beyond useful for guiding planning."

When given a creative, safe space, we found that participants had a broad willingness and eagerness to engage in unsettling conversations about the impact of climate risks on water supplies, socioeconomic dynamics, and environmental resources. Through the SP workshop series, participants acknowledged the range and level of risk to water supplies and could begin thinking about actions, if taken now, to reduce risk. Individually and collectively, participants were ready to embrace a courageous and creative conversation about uncertainty, and ways they could work together to prepare for unexpected future events.

The group acknowledged that a diversity of perspectives, needs, and values is essential to create a well-rounded way of knowing the river and managing water. An openness to both the existence and use of multiple types of knowledge is a key component of decision-making 
processes (Taylor and de Loë 2012). An understanding of and access to different types of knowledge can also help local managers respond to social, economic, and political pressures that arise from the intersection of extreme events (Page and Dilling 2020).

The workshop series revealed that very few people are accustomed to discussing the breadth, complexity, and intersections of the range of issues that affects the Basin. This is in part due to the complexity of the system from social, ecological, economic, physical, and legal angles - and also reflects the diverse ways of knowing (e.g. western scientific approaches and indigenous knowledge rooted in observations of environmental change) (Edelenbos et al. 2011; David-Chavez and Gavin 2018). Examples of the range of complexities mentioned in workshop discussions include:

- Conditions on the mainstem of the Colorado River are different from those in the tributaries.

- $\quad$ The Lower Basin and Upper Basin are managed under different governance structures and have very different issues.

- Water quality and water quantity objectives are often in conflict.

- Recreation interests are often in conflict with habitat and/or water management interests.

- Tribal perspectives have never been fully integrated into any conversation about management at the basin-scale and represent a range of values that differ from water users in the Basin.

- The relationship between the US and Mexico has evolved from historic contention to present collaboration, but that also has the potential to change quickly.

- While the basin-wide conversation is focused on surface water, groundwater is an essential component of the baseflow and is largely ignored in most Colorado River conversations. Groundwater and surface water supplies are coupled, and yet managed in strikingly different ways across the seven states and Mexico. This represents a significant water management problem that requires more attention.

- The system is dominated by experts, official procedures, and communication channels which makes it difficult to engage and contribute new ideas.

Participants also noted the challenge associated with communicating risk. Water managers especially struggle with finding more effective ways to communicate risk without losing public trust and/or causing anxiety among elected officials about political repercussions. There is real difficulty in speaking publicly about risk. For example, focusing on risk could undermine efforts to attract investment, impress a bond rating agency, or keep governance boards happy. As one participant put it, "No water manager is excited to talk about risk in public." However, acknowledging and discussing the range of variability that results from the full spectrum of risks provides managers and stakeholders with a greater capacity to make and fine tune operating decisions (Garrick et al. 2008).

\subsection{Informing SP in the Colorado River Basin and Beyond}

Finally, we consider what these findings might mean for future SP in the Colorado River Basin and beyond. Our SP efforts followed a mixed methods "exploratory" approach to expose the implications of combinations of drivers, their impacts, and the associated solutions (Garfin et al. 2015; Star et al. 2016). Aside from successfully developing storylines associated with a range of possible extreme events, however, the contributions of this project resulted primarily 
from building an emotional commitment to working towards more sustainable solutions. Creating a space for participants to trust each other and learn from each other's perspectives was likely as important as the conversations and storylines themselves. Nonetheless, it is expected that the storylines we produced at a large basin-wide scale can be a starting place for water users in this and other basins to consider in their own processes (Bohensky et al. 2006). While the storylines themselves will need to be amended in the context of different scales, timeframes, sectors or issues within the basin, the approach that we took to developing the storylines provided a direct path to well-reasoned outcomes without compromising the quality of the discussion.

There are implications of this SP effort for other river basins around the world facing similar climatic conditions, bridging disciplines, and building relationships (Scott et al. 2012; Bohensky et al. 2006; Baker et al. 2004). Most SP work that has been undertaken in the past has been conducted in the context of decision processes and planning efforts for specific organizations, businesses, and other entities. These efforts have generally helped to develop convincing and easily communicated paths forward for known decision-makers in specific decision contexts (Schwartz and Ogilvy 1998; Mahmoud et al. 2009). Our process illustrates that SP can also be used in a less structured way, as a means of seeding a broad conversation among a diverse group of people to identify both issues and solutions in a watershed or region that is grappling with uncertainty (Weng et al. 2010). Our version of exploratory scenario planning leading to a collective framework for storylines, even in the absence of a specific decision process, can be valuable for stakeholders and water managers in other basins around the world. It is our perspective that this approach would only work if the participants had a strong collective notion that there were problems to be solved - it would not be likely to work in the abstract (Kang and Lansey 2013; Baker et al. 2004). For example, the context of the CRCP includes concerns about overallocation, climate change impacts on flows, environmental and social stresses and a looming renegotiation process (Udall and Overpeck 2017; US Bureau of Reclamation 2012). Our participants were strongly motivated to participate by their own perceptions that engagement could contribute to creating a framework for future solutions.

These conversations were also evidence of a transformation in the arc of Colorado River Basin water managers' relationship to uncertainty in the context of climate change. Prior to the early 2000's the majority of water managers were either unaware of the evidence related to climate change and its potential impacts on the river, or actively denying its veracity. Once they were exposed (primarily through the efforts of academics, and through their own observations of dramatic water level changes in the reservoirs) to the evidence related to climate change, some individuals embraced it, but the early response was largely denial. In the early days of the transition to acceptance of the "new normal," deterministic predictions of the future (projecting future water demand by multiplying current water use times the population, for example) were commonplace. That perspective has now largely disappeared in the context of massive changes in water use and energy patterns as well as obvious climate change impacts. It is now considered "normal practice" to plan for a range of possible futures. In looking for a particular event that may have catalyzed this transition, one can point to the conversations around Reclamation's 2012 Basin Study (which included SP as a major component) as one of the inflection points in these conversations. Now we can add our experience with COVID 19 to the list of reasons that uncertainty needs to play a central role in planning. 


\section{Conclusions}

Despite the incredible complexity of the Colorado River Basin, through facilitated conversations at conferences and SP workshop series, participants deepened their understanding of the intersecting components of the river system and the people within it. This understanding led to creative ideas and understanding of new perspectives. As neutral conveners with a commitment to broadening engagement in conversations about managing the River, our project team contributed to a more inclusive approach to defining both problems and solutions. Our experience suggests that universities can play a role in creating a functional convening space for hosting difficult conversations about future management of rivers and other natural resources. Although our SP process did not use a traditional approach, it suited the time and place for these conversations. As one of our participants noted, this process allowed "freedom to imagine bolder steps for progress in the basin." We believe that these conversations provided yet another step in our collective awareness that "bolder steps for progress" are both necessary and possible.

We highlight a few major lessons that speak to the value and role of SP for fostering collaboration and creativity. First, we find that process matters for SP. We learned that deliberate efforts to create community among and across sectors has the potential to lead to a better understanding of the range of risks they collectively face as well as a broader array of solutions. It was broadly acknowledged that a diversity of perspectives, needs, and values is essential to create a well-rounded way of knowing rivers and managing water. Second, although there are significant challenges in engaging with uncertainty, complexity, and risk, we learned that exploring these ideas from multiple perspectives can be helpful. In our experience, we found that people could be inspired to talk collectively about low probability but high consequence futures if they have a shared understanding of the magnitude of possible risks. The participants across all of our conferences and SP events expressed concern that tipping points (or "thresholds") in the system remain unexplored and that "signposts" of change need to be identified. Finally, the SP approach appears to have significant potential for application in the Colorado River Basin and beyond. Creating a space for participants to trust each other and learn from each other's perspectives was likely as important as the conversations and storylines themselves. The extreme heat, scant precipitation, and fast-moving fires that defined the summer of 2020 in all seven U.S. Colorado River Basin states may be a harbinger of what lies ahead and the conditions that may serve as a reference point in the re-negotiations of the 2007 Guidelines. Lessons learned from this SP process can fuel continued conversations and future research about risks from such extreme events and spark new partnerships in which diverse interests throughout the Basin can come together to find solutions.

Acknowledgements The project team is grateful to the Janet Quinney Lawson Foundation, the Speer Family Foundation, and National Science Foundation, Grant 1644884 for their support of initial Colorado River "Beyond the Basin Study" conferences, and to the Walton Family Foundation for their support of the Colorado River Conversations Project. The team greatly benefited from J. Keaton Wilson's expertise in designing and creating the graphics throughout the paper.

Author Attribution All authors contributed to the conceptual design of the manuscript, data collection and analysis, and the writing of the manuscript. We also appreciate advice on SP from Ralph Marra.

\section{Declarations}

Conflict of Interest There are no conflicts of interest. 


\section{Example Storyline}

\section{References}

American Rivers and Western Resource Advocates. 2014. The Hardest Working River in the West: CommonSense Solutions for a Reliable Water Future for the Colorado River Basin. At https://www.americanrivers. org/wp-content/uploads/2017/04/CO_River_Solutions_Whitepaper.pdf

Baker JP, Hulse DW, Gregory SV, White D, Van Sickle J, Berger PA, ... Schumaker NH (2004) Alternative futures for the Willamette River basin, Oregon. Ecol Appl 14(2): 313-324

Berggren J (2018) Utilizing sustainability criteria to evaluate river basin decision-making: the case of the Colorado River Basin. Reg Environ Chang 18(6):1621-1632

Bohensky EL, Reyers B, Van Jaarsveld AS (2006) Future ecosystem services in a Southern African river basin: a scenario planning approach to uncertainty. Conserv Biol 20(4):1051-1061

David-Chavez DM, Gavin MC (2018) A global assessment of Indigenous community engagement in climate research. Environ Res Lett 13(12):123005

Dettinger M, Udall B, Georgakakos A (2015) Western Water and Climate Change. Ecol Appl 25(8):2069-2093

Dong C, Schoups G, van de Giesen N (2013) Scenario development for water resource planning and management: a review. Technol Forecast Soc Chang 80(4):749-761

Edelenbos J, Van Buuren A, van Schie N (2011) Co-producing knowledge: joint knowledge production between experts, bureaucrats and stakeholders in Dutch water management projects. Environ Sci Pol 14(6):675-684

Garfin G, Black M, Rowland R (2015) Advancing Scenario Planning for Climate Decision Making. EOS, October 27, 2015. At https://eos.org/meeting-reports/advancing-scenario-planning-for-climate-decisionmaking

Garrick D, Jacobs K, Garfin G (2008) Models, Assumptions, and Stakeholders: Planning for Water Supply Variability in the Colorado River Basin. First published: 30 January https://doi.org/10.1111/j.1752-1688. 2007.00154.x

Gober P, Sampson DA, Quay R, White DD, Chow WT (2016) Urban adaptation to mega-drought: Anticipatory water modeling, policy, and planning for the urban Southwest. Sustain Cities Soc 27:497-504

Gober P (2014) Decision Making Under Uncertainty: A New Paradigm for Water Resources Planning and Management. In: Wang L, Yang C (eds) Modern Water Resources Engineering. Handbook of Environmental Engineering, vol 15. Humana Press, Totowa

Gober P, Wentz EA, Lant T, Tschudi MK, Kirkwood CW (2011) WaterSim: A Simulation Model for Urban Water Planning in Phoenix, Arizona, USA. Environ Plann B: Plann Design 38(2):197-215

Gober P (2008) Climate adaptation and water resource management in Phoenix. Water Resour impact 10:10-13

Groves DG, Davis M, Wilkinson R, Lempert R (2008) Planning for climate change in the Inland Empire: Southern California. Water Resour IMPACT 10(4):14-17

Hoff H, Bonzi C, Joyce B, Tielbörger K (2011) A water resources planning tool for the Jordan River Basin. Water 3(3):718-736

Intergovernmental Panel on Climate Change (IPCC) (2008) Fourth Assessment Report. Glossary. Climate Change 2007: Synthesis Report. IPCC Press

Kaatz L, Waage M (2011) Denver Water's Approach to Planning for Climate Change. Water Resour Impact 13(1):5-7

Kang D, Lansey K (2014) Multiperiod planning of water supply infrastructure based on scenario analysis. J Water Resour Plan Manag 140(1):40-54

Kang D, Lansey K (2013) Scenario-based robust optimization of regional water and wastewater infrastructure. J Water Resour Plan Manag 139(3):325-338

Karambelkar S, Gerlak AK (2020) Collaborative Governance and Stakeholder Participation in The Colorado River Basin: An Examination of Patterns of Inclusion and Exclusion. Nat Resour J 60(1):1-45

Kuhn, E. and Fleck, J. 2019. Science be dammed: how ignoring inconvenient science drained the Colorado River. The University of Arizona Press.

Lautenbach S, Berlekamp J, Graf N, Seppelt R, Matthies M (2009) Scenario analysis and management options for sustainable river basin management: application of the Elbe DSS. Environ Model Softw 24(1):26-43

Li YP, Huang GH, Chen X (2009) Multistage scenario-based interval-stochastic programming for planning water resources allocation. Stoch Env Res Risk A 23(6):781-792

Mahmoud MI (2018) Climate Adaptation Planning in Central Arizona for Long-term Water Supply Reliability. In AGU Fall Meeting Abstracts

Mahmoud M, Liu Y, Hartmann H, Stewart S, Wagener T, Semmens D et al (2009) A formal framework for scenario development in support of environmental decision-making. Environ Model Softw 24(7):798-808 
Mahmoud MI, Gupta HV, Rajagopal S (2011) Scenario development for water resources planning and watershed management: Methodology and semi-arid region case study. Environ Model Softw 26(7):873-885

Maier HR, Guillaume JH, van Delden H, Riddell GA, Haasnoot M, Kwakkel JH (2016) An uncertain future, deep uncertainty, scenarios, robustness and adaptation: How do they fit together? Environ Model Softw 81: $154-164$

Marra R, Thomure T (2009) Scenario Planning: Making strategic decisions in uncertain times. Southwest Hydrol $3: 22-23$

Means ED, Patrick R, Ospina L, West N (2005) Scenario planning: A tool to manage future water utility uncertainty. J-Am Water Works Assoc 97(10):68-75

Milly PC, Dunne KA (2020) Colorado River flow dwindles as warming-driven loss of reflective snow energizes evaporation. Science 367(6483):1252-1255

Moore SS, Seavy NE, Gerhart M (2013) Scenario planning for climate change adaptation: A guidance for resource managers. Point Blue Conservation Science and California Coastal Conservancy

Mott Lacroix K, Hullinger A, Apel M, Brandau W, Megdal SB (2015) Using scenario planning to prepare for uncertainty in rural watersheds

National Research Council (2016) Attribution of Extreme Weather Events in the Context of Climate Change. The National Academies Press, Washington, DC

Nelson G, Bennett E, Berhe A, Cassman K, DeFries R, Dietz T, ... Zurek M (2006) Anthropogenic Drivers of Ecosystem Change: An Overview. Ecol Soc 11(2)

O’Connor MH, McFarlane M, Fisher J, MacRae D, Lefroy T (2005) The Avon River Basin in 2050: scenario planning in the Western Australian wheatbelt. Aust J Agric Res 56(6):563-580

Page R, Dilling L (2020) How experiences of climate extremes motivate adaptation among water managers. Clim Chang 161:499-516

Pallottino S, Sechi GM, Zuddas P (2005) A DSS for water resources management under uncertainty by scenario analysis. Environ Model Softw 20(8):1031-1042

Pulwarty, R.S, K.L. Jacobs, and R.M. Dole, 2005. The hardest working river: Drought and critical water problems in the Colorado River Basin, in Drought and Water Crises: Science, Technology, and Management Issues, ed. Don Wilhite. Marcel Dekker, New York.

Sampson DA (2015) Mega drought in the Colorado River Basin, water supply, and adaptive scenario planning for the Phoenix Metropolitan Area; simulations using WaterSim 5. In AGU Fall Meeting Abstracts

Schwartz P, Ogilvy JA (1998) Plotting your scenarios. In: Fahey L, Randall R (eds) Learning from the Future. John Wiley \& Sons, New York, pp 57-80

Scott CA, Bailey CJ, Marra RP, Woods GJ, Ormerod KJ, Lansey K (2012) Scenario Planning to Address Critical Uncertainties for Robust and Resilient Water-Wastewater Infrastructures under Conditions of Water Scarcity and Rapid Development. Water 4:848-868

Star, J., Rowland, E. L., Black, M. E., Enquist, C. A., Garfin, G., Hoffman, C. H., ... Waple, A. M. (2016) Supporting adaptation decisions through scenario planning: Enabling the effective use of multiple methods. Clim Risk Manag 13: 88-94

Stern, C., Sheikh, P. (2020). Management of the Colorado River: Water Allocations, Drought, and the Federal Role. Washington, DC: Congressional Research Service Report R45546

Stratus Consulting and Denver Water (2015) Embracing Uncertainty: A Case Study Examination of How Climate Change is Shifting Water Utility Planning

Taylor B, de Loë R (2012) Conceptualizations of local knowledge in collaborative environmental governance. Geoforum 43:1207-1217

Udall B, Overpeck J (2017) The twenty-first century Colorado River hot drought and implications for the future. Water Resour Res 53(3):2404-2418

US Bureau of Reclamation (2012) Colorado River basin water supply and demand study: Study report. US Department of the Interior Bureau of Reclamation

US Bureau of Reclamation (2019) The Law of the River. U.S. Department of the Interior Bureau of Reclamation. https://www.usbr.gov/lc/region/g1000/lawofrvr.html

US Bureau of Reclamation (2020a) Colorado River System 5-Year Projected Future Conditions - April 2020 Study. US Department of the Interior Bureau of Reclamation

US Bureau of Reclamation (2020b) Colorado River System 5-Year Projected Future Conditions - August 2020 Study. US Department of the Interior Bureau of Reclamation

US Bureau of Reclamation \& Ten Tribes Partnership (2018) Colorado River Basin Ten Tribes Partnership Tribal Water Study: Study report. US Department of the Interior Bureau of Reclamation

US Secretary of the Interior (2007) Record of Decision: Colorado River Interim Guidelines for Lower Basin Shortages and the Coordinated Operations for Lake Powell and Lake Mead. US Department of the Interior Bureau of Reclamation 
US Department of the Interior (2020) Drought in the Colorado River Basin. Open Water Data Initiative. US Department of the Interior Bureau of Reclamation

VanRheenen NT, Wood AW, Palmer RN, Lettenmaier DP (2004) Potential implications of PCM climate change scenarios for Sacramento-San Joaquin River Basin hydrology and water resources. Clim Chang 62(1-3): $257-281$

Waage MD, Kaatz L (2011) Nonstationary water planning: an overview of several promising planning methods. J Am Water Resour Assoc 47(3):535-540

Weng SQ, Huang GH, Li YP (2010) An integrated scenario-based multi-criteria decision support system for water resources management and planning-A case study in the Haihe River Basin. Expert Syst Appl 37(12): $8242-8254$

Publisher's note Springer Nature remains neutral with regard to jurisdictional claims in published maps and institutional affiliations.

\section{Affiliations}

\section{Andrea K. Gerlak ${ }^{1} \cdot$ Katharine L. Jacobs ${ }^{2} \cdot$ Amy L. McCoy $^{3} \cdot$ Season Martin $^{4} \cdot$ Mariana Rivera-Torres $^{5} \cdot$ Anna M. Murveit ${ }^{6} \cdot$ Amanda J. Leinberger $^{7} \cdot$ Timothy Thomure $^{8}$}

1 School of Geography, Development and Environment; Udall Center for Studies in Public Policy, University of Arizona, Tucson, AZ, USA

2 Department of Environmental Science, Center for Climate Adaptation Science and Solutions, University of Arizona, Tucson, AZ, USA

3 Martin \& McCoy, LLC, Tucson, AZ, USA

4 Martin \& McCoy, LLC., Tucson, AZ, USA

5 Consensus Building Institute, Tucson, AZ, USA

6 School of Natural Resources and the Environment, Tucson, AZ, USA

7 Center for Climate Adaptation Science and Solutions, University of Arizona, Tucson, AZ, USA

8 Tucson Water; School of Geography, Development and Environment, University of Arizona, Tucson, AZ, USA 